\title{
The Collocation of Plasmas Within the Cell-I*
}

\author{
A Survey of a Mechanical Theory of Heredity \\ By Dr. Louis Legrand
}

IN spite of the title given above this article is not a revival of the simplist and multisecular belief in the collocation of germs. The fact is that science has made remarkable progress since the

the Spermatists was settled.

But since everything seems to have been said upon a subject which is so vast and has been so thoroughly investigated we necessarily come in contact with older theories which are chronologically superposed without having entirely disappeared, and far from having mutally destroyed each other, reciprocally support each other at certain points. It is also true that biologists can make here and there certain inevitable, through fragmentary approximations to the notable and sometimes classic ideas of Darwin, Brooks, Weissmann, Delage, Hallez, Hertwig, Naegeli and De Vries among others.

The peculiar innovation consists in an attempt at the figurative representation of the structure of the substances which we have come to believe are factors in mathematical graphic and the microscopic reality, mathematical graphic and the microscopic reality, should be sufficiently flexible to enable us to grasp at
once the general and the particular, to adapt itself to the multiple tasks which the theory has in view, if we attempt in this overgrown thicket of biology "to explain the Visible Complicated by the simple Invisible," according to the desire of one of eminent physicists.

\section{i-Cellolar and NUClear plasmas}

We take our start from the well-known descriptions of the cell and the nucleus aside from histologic formations (membrane, nuclein, centrosome, vacuoles, inclusions, leucites, pigments) which are neither universal nor plasmas, cytoplasma, in which is enclosed a rather plasmas, cytoplasma, in which is enclosed a rather limited, more refractive, more colorable nucleus for
of very analogous plasmas, nucleins or chromatines.

Although at the present time there is no single plasma of any given species whose chemical composition in the living state is completely known, yet we have data sufficient to enable us to form an idea of this constitution. If the cell is not exactly, as Pflueger said, "a giant molecule," yet its plasms are an assemblage of large molecule," yet its plasms are an assemblage of large molecules, all of which are known in the isolated state;
they have nothing qualitatively specific, since they exist in both domains, they are of the order of the amid acids (leucine type, glycocolle) with the nucleic acid as the fundamental nucleus (Kossel and Matthews). The enzymes, for example, plasmatic fragments already voluminous, are a complex of molecules of the first order (lecithine type, albumoses, nucleo-proteids), to which are adjoined several groups of molecules of the which are adjoined several groups of molecules of the neurine). These voluminous compounds are in their turn united with each other by identical masses which repeat themselves a great number of times in a given protoplasm. ${ }^{1}$ Just as in a mosaic of square tiles the same designs are repeated, formed of the same number of the same kind of cubes of colored stone at the same distance from each other, and in the same position.

This cell is of the average type, not too much differentiated, not too much denatured from the composition type by the functional specialization which gives preponderance to certain principles (glycogen, fats, zymases, mucus, protagons) at the expense of the albuminoids of the species; we can, therefore, make an abstraction of the types wherein such a "functional chemical conthe types wherein such a "functional chemical con-
stitution" surpasses and eclipses the specific zoologic stitution" surpasses and eclipses the specific zoologic
constitution (for example, of the genre of the cytases of Besredka) common to all of the cells of the organism under consideration.

What is there then which is specific for the constituents of the cellular plasmas, for these substances so ubiquitous and so abundant, which chemistry discovers in slightly varying proportions in the humors of animals? There can be nothing specific except their number and particularly their method of reciprocal union, their mode of fixation to the principal neuclei whose accumulation by thousands produces a cytoplasm. The plasmas thus united with each other in the cell, during the life of the individual, merit the name of fixed plasmas, for this

\section{* Revue Générale des Sciences.}

'We are authorized to accept this repetition in particular by the consideration of the results of the experimental or physiologic rragmentation of cortain ovules in whlch oach fragment retalns embryo. association is, by definition, correlative of the death of the cell, and if it is generalized throughout produces the death of the organism itself. But fixation is not synonomous with crystalline rigidity, whether the large constituent molecules are sufficiently numerous for their displacements to accommodate themselves to the general movements of commodate themselves to the general movements of
living, elastic, viscous and mobile plasmas, or whether this mobility remains compatible with certain temporary molecular "defixations," with automatic attachmen without fundamental alteration of the etructure of the whole; for the definite fragmentation coincides, of course, with cellular death with the liberation of numerous molecular links and with the appearance of coloring aptitudes unknown in life.

The nucleus has not a fundamentally different constitution. This central spheroid, which can be easily discerned in a living state without the artifice of coloration, is formed of nucleins closely resembling the vitellines (Tichomiroff), molecular blocks of the same order as those of the cytoplasm, but flanked by a larger proportion of metallic or metalloidic appendices in a more or less dissimulated condition.

We must give up the idea of considering nuclear and cellular plasmas as of opposite chemical constitution and the process occurs according to Kolliker, Prennant, net works of the cytoplasm and the nucleus. It must be remembered, however, that these two substances are evidently not miscible, in the living and physiologic state, in the quiescent cell; moreover, Loeb and Carracido have in the quiescent cell; moreover, Loeb and Carracido have of a nuclear substance and of the cytoplasm, as if it were a case of the inverse magnetization of the extremities of a single core wound about itself.

\section{II-FIXEd AND NON-FIXED CHARACTERS}

The most superficial observation of heriditary forms and manifestations among living creatures, among the innumerable characteristics which may define the individual, and which are constantly transmitted, enable us to distinguish two sharply differentiated groups of very unequal importance. The first are the fixed characters which undergo no change as concerns two living creatures nor from one generation to the other; the four limbs and the hair in a mammal, retractile nails in carnivora, a single occipital condyle and feathers in a bird. These characteristics form the basis of classifications. They are subject to the laws of correlation and the more considerable the portion of the body of the animal which they concern the more unalterable they are. They are, therefore, multicellular, very rarely of the histologic order of the Metazoa. The tooth, which is at once a tissue and an organ, is a type of these much employed in classification. The fixed characters are the specific characters.

The others, those which change from one animal to another in the same species, or from one generation to the other, are the non-fixed characters. They are arranged in the following four classes:

1. - The sex and the secondary sexual characters.

2.-The characters of the race or of the variety. An example in the human species: the color of the skin, of the hair, of the iris, the pigment content of the epidermic cells, the form of the cross-section of the hairs, the cranial, nasal and maxillary indices which constitute the facial physiognomy of each race; steatopygia, the Mongolian blue spot; the average height and circumference; and finally the immense gamut of psychic aptitudes of each race; these are characters which were always transmitted when the consorts are of the same race.

3.- The third group, which is intermingled by insensible transitions with the preceding group, comprises characters which are strongly sporadic in the species, superficial and of minimum morphological importance, and which are irregularly transmitted. I concerns ancestral or atavistic character; it is rather their mode of appearance and of hereditary apportionment in lines of descent which merits this name than their peculiar value, for there is nothing to prevent them from becoming racial characters in time. They are of ten of a semi-pathologic or teratologic order. Examples In the human species, baldness, sexdigitism, hemophilia and most of the diatheses compatible with fecundity certain psychological characters, mathematical o musical aptitudes; facial features especially (the nose of the Bourbons) and a large number of external characte which are delicate of estimation and difficult to express in figures, but which are very well known and appre- ciated by breeders and also in the human species (coarseness or fineness of extremities), etc.

4.- The last group comprises the almost infinite variety of the individual characters of the immediate parents; their transmission is sometimes very precise, sometimes entirely lacking. Their type is in the naevi, in the details, at times very minute, of the face or the body, in the quality of muscular and arterial tissues and of the glands; the majority of diatheses of lymphatism and the whole gamut of temperaments; the hemorrhagic diatheses, the neuroses, certain psychoses, longevity, sensorial qualities or defects, myopia, possibly Daltonism especially when these are favored by consanguinity. especially when these are favored by consanguinity.
This heredity can be pursued even into histologic details, as is indicated by the family resemblance in the arrangement of the papillae of the ends of the fingers so much utilized in anthropometry. This last group naturally involves all the pecliarities and accidents concerning which there is so much discussion as to whether they are susceptible of transmission as rcquired characters. The difference of importance between the fixed characters and the others is obvious; it makes little difference what causes a horse to be black or white, heavy built or rapid, a draught horse or a racer; it makes much difference what causes it to be a vertebrate, a quadruped, one of the herbivora, a soliped. What plasmas, the

\section{FIXEd AND NON-FIXED PLASMag}

LOCALIZATION AND VALUE

We have elsewhere defended the following opinion, which is moreover not absolutely new, that the fixed or specific characters, infinitely more numerous than the others, must be represented materially in organisms by an identical substance in all representatives of the Specific Plasma. We have come to deny to any given specific plasma an elective localization in a particular tissue or organ, but to consider it as universally distributed in the only element common to all organisms and to all the parts of a given organism, i. e., in the cell. This substance, forming the support of the most numerous and the most important characters, must preponderate also in material mass with relation to other plasmas which are the support of variable characters; it is principally for this reason that we have identified it approximately, and without the necessity of very great histologic precision, with the hyalin cytoplasm, nonspecialized and slightly chromophilous, of every living cell. Cytoplasm, therefore, is a synonym for fixed plasma, the material substratum of the fixed characters. Another very important consideration is the following: These plasmatic blocks, histologically separate, which we call cells, are in reality "fixed," the ones to the others, we call cells, are in reality "fixed," the ones to the others,
by their similar faces, by this substance identical with itself which is the cytoplasm; and this reciprocal fixation, which is very solid and fundamental in life, permits the existence of the tissues, the organs, and the substances of all the polyplastids. Hence, there is a flagrant antagonism, both histologic and bislogic, between the cytoplasms, which are constantly fixed, the one to the other, and the nuclei which are never so fixed, which, in other words, are always defixed with relation to each other.

Moreover, the nuclear chromosomes, at certain crises of the cellular life, on the occasion of each cytodiaeresis, defix themselves even from the surrounding cytoplasm, after having undergone a series of transformations which makes them the type of the variable organs of the cell. The chromatic apparatus, therefore, is constituted of nonfixed plasmas (fixed neither to each other nor to the cytoplasmic block), vehicles or material supports of non-fixed characters.

And observe that these distinctions will find themselves amplified and rendered striking in the two cellular types most interesting from the point of view of Heredity, in the ovule and the spermatozoon.

Each specific plasma, the irreversible and almost immutable material substratum of the species, is found identical in all the living cells, but the necessities of the division of physiologic labor have caused it to accumulate with predilection and at times with prodigality in that

2The idea of a plasma proper to each species is found here and there in the works of many modern biologists: Brooks, M. F. Guyer, C. H. Richet, Leduc, Le Dantec, Gautior, Dastre, E. B. Wilson, Lilie, Concklin, Fick, Loeb, Hallion, Benedikt. It has been made the subject moreover of a more profound investigation.
(Legrand, The Selection of a Specific Plasma. Malolne, 1916.) 
voluminous cell which we call the ripe ovule. It is formed evidently of old racial plasmas fixed and immobilized at their time in the course of the indefinitely prolonged life of a plant or animal phylum. But it is only artificially that we could think of dissociating it into its constituent elements, which form today, in substance and in mode of fixation, a perfect and definite amalgam. ${ }^{3}$ The same molecular groups, chained to each other and to their neighbors, in a certain fashion which govern, in embryogenesis and then in ontogenesis, the

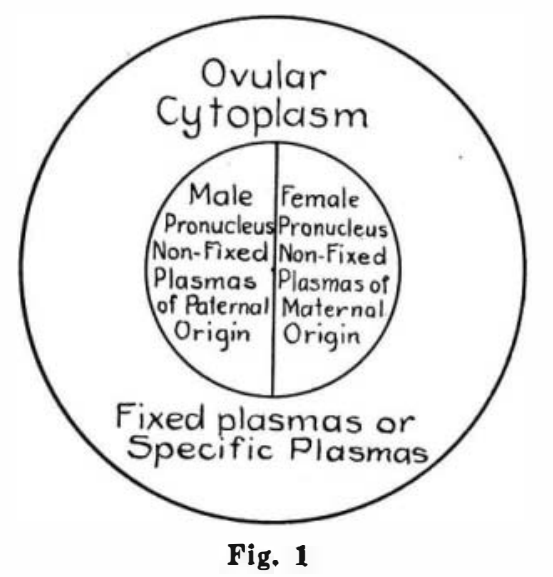

nature of the dentition, the form of the condyles, the presence of retractile nails in the Carnivora Felidae, must be found in each ovule of this animal type, but they are never isolatedly dissociated in a viable being; and the study of certain organordal teratoma, or tumors with multiple tissues, shows us that if these monstrous productions succeed in developing they constantly retain the specific type as far as concerns the teeth, the hair the skin, certain glands, the visceral fragments, without ever arriving at tissues or organs proper to a related or a non-related species.

It would certainly be very fine and most satisfactory to the mind it some unforeseeable artifice should permit the trace of the geologic ancestors of the animal studied to appear in this specific block, the organo formativ relationships with groups extinct or near, but engaged in another evolutionary direction. This hope is not unrealizable theoretically, since certain easily discernible chemical affinities have been recognized between animals belonging to groups which one would have believed to be artificial (precipitins common to the Sauropsidae) and since the serum of living elephants is agglutinated by extracts from the congealed flesh of Siberian mammoths; but nothing authorizes us at the moment to hope to discover in these specific cytoplasms the traces of some molecular sedimentation or visible plasmatic imbrications corresponding to characters progressively acquired throughout the ages, characters of family, of class, of throughout the

order, of branch.
Such is the idea which we are now permitted to form of the cytoplasm of the egg before fecundation.

This cytoplasm envelops and contains a nuclear mass, long since described, visible in the living state, which must represent materially the four types of non-fixed characters concerning the female bearing this ovule, her ascendants, and her race; physiologists are now agreed in considering this ovular chromatine as the plasmatic and dynamic equivalent of the spermatozoon and this "homodynamics" (Weissmann) is the expression of this perception old as the Auman observation of the possible equality of influence of the two parents on the offspring.

And now what is the spermatozoon?

From the point of view which here interests us it can be given a definition which is at once very exact and very suggestive: the spermatozoon is the only living element now fixed to the soma; $i$. e., susceptible of being separated from the soma and still remaining alive

We are thus quite naturally led to behold in the spermatozoon, for any given species, a principal or exclusive vehicle of the non-fixed plasmas, $i$. e., that it must materially represent the four types of non-fixed characters concerning the male from whom it emanated, his ascendants, and his race.

'With the exception of the Hybrids, which we will conside later

There is nothing absolute in this role, the result of the divisio of physiologic labor, which can be pushed more or less far. A complete review of the possible types of male gametes would commence with those which are the vehicles solely of the individual plasmas of the male (Brooks' theory), would base itself upon th with a less refned type, closer to any somatic cell whatever, incompletely lightened of cytoplasm, which would be sometimes distinct histologically from the spermatic chromatine (various appendices, undulating membranes), and sometimes indistinct. Since the tail, almost constant in the animal kingdom, is a cytoplasmic relic, we may say that every spermatozoon carries with it some more or less tenuousportion of the cytoplasmo. It is easy to
V-THE Stratification OF PLAsMas IN THE AMPHiMIXIC CHROMATIN

Having thus stated this quite novel presentation of the isolated sexual elements, let us follow them in the course of cytologic fecundation and try to fathom the consequences.

The spermatozoon, obeying that positive chemitaxis which Delage has demonstrated to be peculiar to the cytoplasm of the egg, even after the expulsion of the female nucleus, penetrates the egg at a point on it distinct from the two others, merits the name of original trinitary block (Fig. 1). We remark that it agglomerates together a great mass of plasmas fixed during the whole life of the individual and of the species, with two small masses of plasmas which ure non-fixed during the life of the species, but which we must believe to be thenceforward fixed (physiologically if not histologically) during the life of the individual; $;$ the indispensable postulate consists in admitting that those plasmas tend to resume their original mode of fixation with respect to

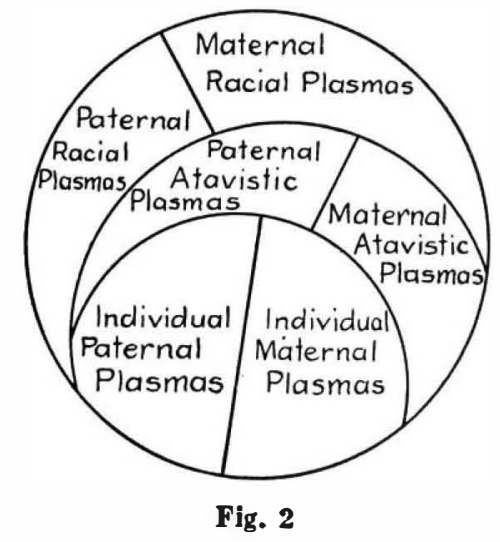

surface which extends itself upon encountering it into a "cone of attraction," the histologic evidence of thi chemitactic action: we know that this force is exerted at a certain distance and that two ripe eggs of different species, placed in a mixture of the fecundating fluid of their species, will, in a healthy condition, effect an exact selection of the spermatozoa which corresponds to them. The formation of the vitelline membrane and the cessation of the chemitactic attraction, constitute, im mediately after this penetration, an ensemble of obstacles

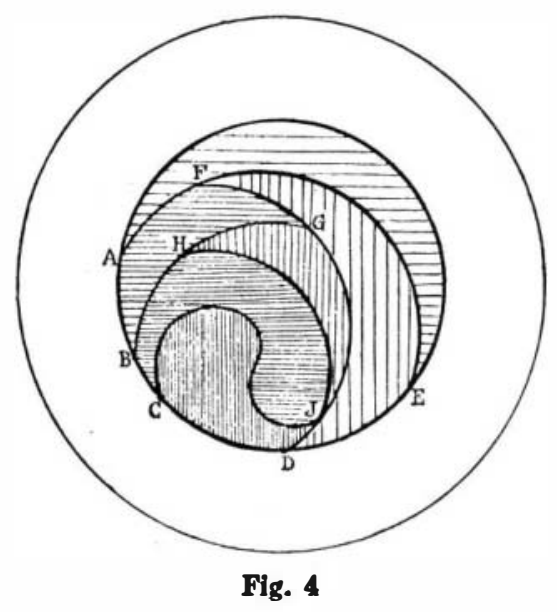

which, in a healthy condition, opposes the entrance of another spermatozoon.

Neglecting at present the role of the Centrosomes (spermocenter and ovocenter) which is still a matter of controversy and has not certainly the generality at tributed to it by $\mathrm{H}$. Fol, there remains as a certain phenomenon the junction of the two pronuclei composed of the same number of chromosomes, at the center of the egg or very near that center, the male element having traversed the cytoplasm throughout its thickness.

The cytologic amphimixia is accomplished.

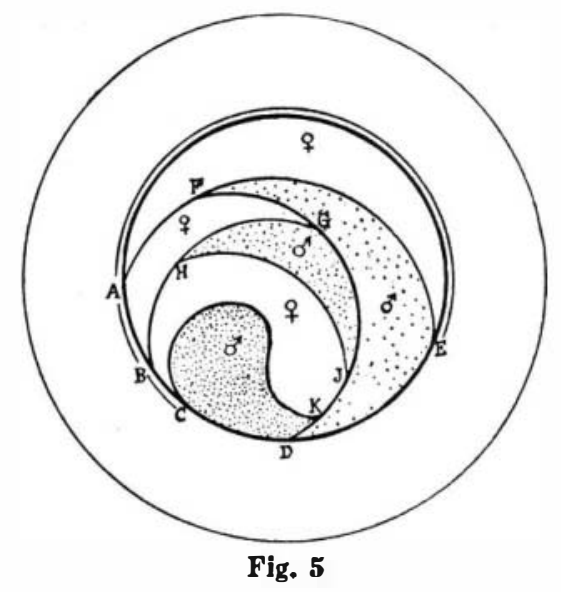

We are now in the presence of a specific block within which are included: A small block of non-fixed plasmas of maternal origin, and joined to this the small block of non-fixed plasmas of paternal origin, the remainder of the head or chromatin of the spermatozoon.

Such a plasmatic tread, in which each component possesses at the beginning its own individuality and its own material limits, and recovers them, if it loses them at certain moments of the cellular life, then becoming again

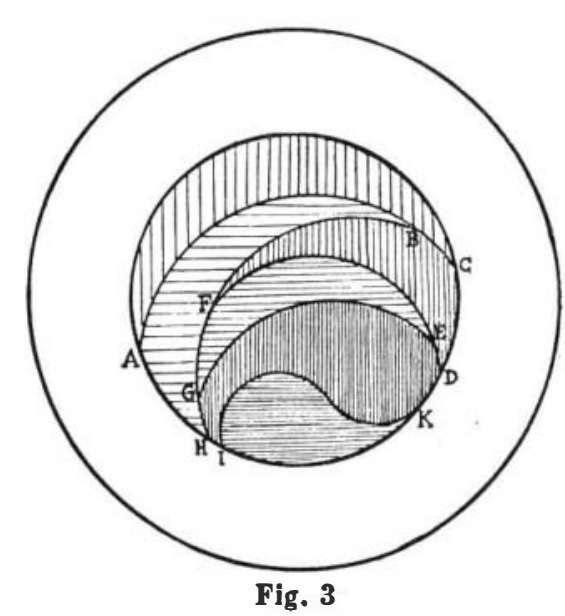

the two other plasmatic blocks, every time that they are deranged, displaced, defixed, $i$. $e$., in the course of each of the ulterior karyokinetic crises, universal factors of all embryogenesis and of all morphogenesis among the polyplastids.

These plasmatic masses of different origin which have arrived in contact in the common nucleus (nucleus of segmentation), cannot arrange themselves by chance; they must mutually arrange themselves, starting with the concave surface enveloping the specific cytoplasm in a certain order, of which figure 2 gives an approximate idea, and this order will probably be the age of the fixation with respect to this ancient plasma, the plasmas of more recent acquisition being the most central, and the racial plasmas the most peripheral, and occupying the largest surface of fixation with the specific enveloping block.

Moreover, there occurs, literally, a reciprocal arrangement of plasmas of the same age, of the same dynamic value, of the same ancientness proceeding from each genitor, the paternal racial plasmas joining with the maternal racial plasmas, the paternal atavistic plasmas maternal racial plasmas, the paternal atavistic plasmas
with the maternal atavistic plasmas, with the paternal individual plasmas with the maternal individual plasmas.

But this figure is too diagrammatic. It does not indicate that we are dealing here particularly with plastic substances, movable with respect to each other, and subjected to reciprocal excentric and concentric pressures. In reality the plastic cap-shaped areas of the $P$. $R$. (racial plasma) and the P. At. (atavistic plasma), of each sex are not squarely in contact, but narrowed at the edges and overlapping in the manner of a plant bulb, at times, indeed, overlapping to such an extent as to become enveloping. And, if it is true, as we are taught by the history of the development and the peculiarities of heredity, that each non-fixed character preserves its individuality in the product until the end of growth, then the corresponding plasmas must preserve it also in the composite chromatines after the first, that of the egg, which we will describe presently: it is necessary then that, for example, the paternal racial plasmas should overlap the maternal racial plasmas, or inversely; it is necessary that the maternal atavistic plasmas should overlap the paternal atavistic plasmas, or inversely, as indicated in Figs. 3 and 4 where the plasmas of each sex are imbricated alternately, those of male origin crosshatched vertically, those of female origin horizontally.

By according to these different plasmas minute differences of density, of miscibility, of mobility, we can easily succeed in imagining the reciprocal collocation of these caps, segments of an irregular spheroid with curved surfaces, the oldest crowded up towards the surrounding specific plasma, envelcping the more recent as an acquisition or as a facility of fixation to the total block. This is the collocation of plasmas, far more fruitful as an explanatory value than the collocation of germs, since it enables us to enclose the whole hereditary substratum in a small number of material figures, which we can, if
not directly behold, at least identify, as colorable, meas.

sAccording to De Vries the fusion of the male and female substances is never complete; it may even be very imperfect, as in the Cyclops or the Crepidula, in which the nuclei present, during a large part of the somatic existenco

The flxation in their position of the plasmas, after the penetra tion of the spermatozoon, depends upon the well-known law of W. Roux, O. Schultze, Brachet, that the plane of penetration of the spermatozoon in the egg governs the frst plane of segmentation
and determines the plane of symmetry of the blastula. 
urable, delimited plasmatic masses, which have hitherto remained without precise biolcgic signification, without specific affectation to the transfer of any given character.

$$
\text { v - LATENT CHaRACTERS }
$$

Still continuing to follow the logical exploitation of the sole directing postulate of the whole present theory, we must now admit that what matters from the viewpoint of the proportional part of the racial, atavistic, or individual plasmas transmitted by each genitor, is, in the

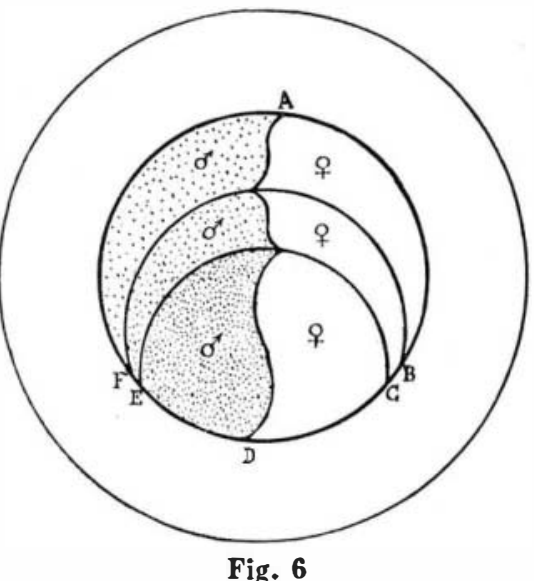

Fig. 6

diagram, as in reality, the extent of the surface of contac and therefore of fixation of each of these plasmatic blocks with the envelope of fixed plasmas: whence there results for them an order of involution and of evolution and crder of complication of plasmatic planes, and by consequence - in a certain measure -an order of appearance of corresponding characters, and also by consequence an eclipse, an inhibition of the characters whose vehicle are the plasmas which have remained in the interior or at the free extremity of the filament.

This is the entirely simple explanation of how characters may be latent and yet transmitted: it is because their vector plasmas are, themselves, not latent; there are no plasmas latent, but without contact, or separated from the zone of adhesion, from the deep-rooted and active zone which separates or unites the fixed plasma and the non-fixed plasmas, from that "historic" zone from that zone of manifestation which thenceforth governs the relations of the cytoplasm and the nucleus, these plasmas have no dynamic value in the ontogenesis of the product at present under consideration. Thus, at the origin of every creature, a very important portion of the plasmas can be effectively transmitted, yet play no part in the morphogenesis because it is not involved in the zone of fixation. But these plasmas are only momentarily "defixed" and may become again fixable and active in an ulterior amphimixis. Thus must be solved the celebrated apparent antinomy of a genitor transmitting to his descendants characters which he himself does not bear.

vi. THE PLASMatic COLLOCATIONS AND THE MaNifESTaTION OF CHARACTERS

If we consider the large surface of contact of the racial plasmas, their expansion into a vast enveloping cap, we must admit that of all the non-fixed characters it is these which are most numerous and which appear most con stantly. It is doubtless this which happens, in fact, and if the genitors are of the same race these racial characters will all be present, being pushed into the active zone by one or the other of the identical masses of each sex Consider for example the great extent of the useful surface which they occcupy in Fig. 3, adding the zone of maternal origin $\mathrm{A} \mathrm{H}$ to the large semicircle A C provided by the paternal plasmas.

If they are not of the same race there will be a mixture of characters of the two races with every known proportion of hybridization.

Next in importance and frequency of transmission to the racial characters come the individual paternal and maternal characters. Here the very extended maternal plasmas in I $\mathrm{K}$ overlap the two modest extensions $\mathrm{H}$ and $\mathrm{K} \mathrm{D}$ of the paternal individual plasmas: whence comes the proportional predominance of the maternal resemblances.

Finally, in the last case, and more rarely, even to the extent of sometimes passing for biologic curiosities, the atavistic characters may possibly come to the front and almost constantly attach themselves to one of the ancestral sides to the exclusion of the other, as is a commonly observed fact in families. These characters will be manifest in small numbers when the edge of one of the intercalary caps whi $h$ bear them, compressed between the two preceding plasmas, begins to come in contact with some part of the specific block and adhers to it by a few points which are necessarily very limited. In this cas the maternal atavistic characters are eclipsed, inoperative, the block G F E being completely enclosed, while the atavistic characters on the paternal side will be of some importance thanks to he zone of adhesion of the block F B C D to the block C D.

The fecundated ovule of the opposite type will therefore determine for the individual which is born from it the following hereditary characters, taking into account for the sake of ease of description only the linear relations of the figure and not the real relations of the curved surfaces of which these lines are the projections:

1.-The enormous predominance of the paternal racial plasmas in the ratio five to one, the ratio between the

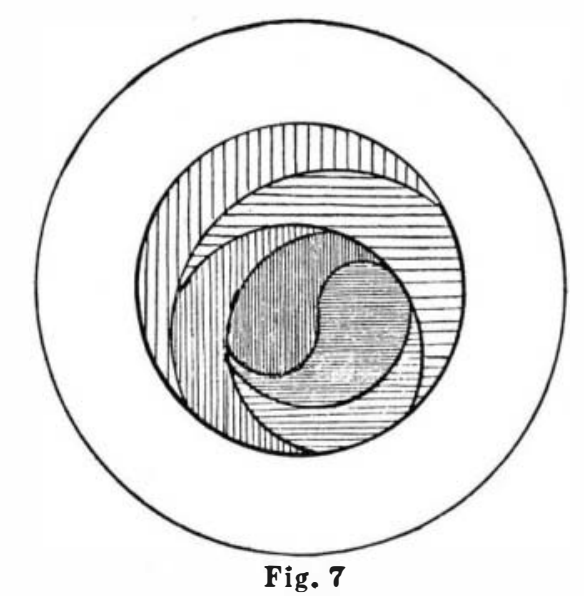

zone of fixation A C and the zone A H. This will be of no impor

reties. 2.- No ancestral character on the maternal side: but
these characters though latent and eclipsed in this in these characters though latent and eclipsed in this in-
dividual may reappear in one of its offspring; a fe dividual may reappear in one of its off sp
atavistic characters of the paternal branch.

3.-A few individual characters of the father lost in a mass of

Suppose, for example, that the meeting of the two

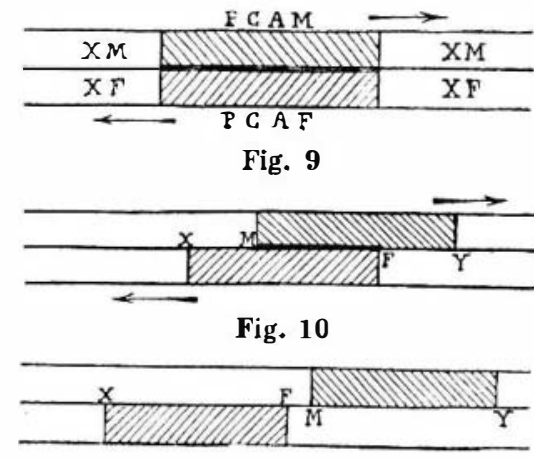

Fig. 11

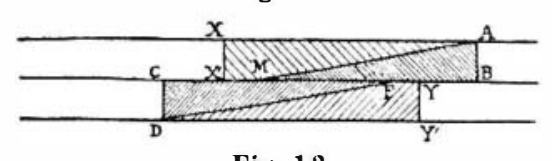

Fig. 12

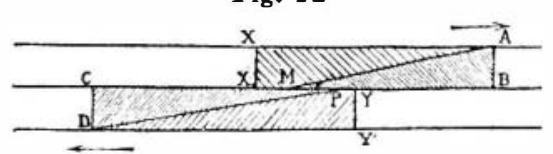

Fig. 13

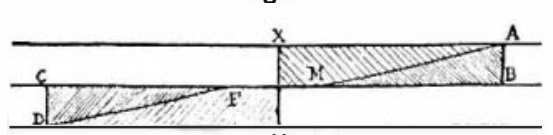

Fig. 14

chromatines is produced under a slightly different angle; it might have given rise to an amphimixic plasmatic type in which the enlacement of the homologous plasmas is totally rearranged with respect to the preceding, like that shown in diagram in Fig. 4, in which the plasmatic contacts are almost everywhere the inverse of those in Fig. 3. It concerns, however, two fecundated ovules of the same species, of the human ovules, if you like. Compare the extent of the lines, the nature of the curves, the importance of the surfaces, the points of contact, the zones of coincidence of two surfaces, or of the two lines which represent them-everything has been changed. A type of plastic architecture of this kind is made so definite, and by so many points and surfaces, that it may be considered as unique among millions and millions of possible combinations. In this ideal section : $f$ the egg, which is a plane, that of the figure, the simple broken line composed of the curves A F, G H, H J, J C if we take into account the respective distances of each point, already possesses a marked individuality and it would be singularly rash to hope to find by chance one exactly similar; and we must not forget that all these slidings, adhesions, and fixations operate not merely in one plane, but in the three dimensions of space, between material spherical caps of a given thickness, dimension and curvature; and that naturally these caps are not limited to the diagrammatic number of five or six, but are superposed upon each other in great numbers, by hundreds or possibly by thousands. The biologist most difficult to convince ought to recognize therefore, when he recalls the complexity and the precision of the chemical structure of living substance, that we have here, not an improvised explanatory artifice, but a graphic representation of an infinitely complicated real, plasmatic structure capable of condensing characters into an infinitely small volume, that is, the possibilities of evolution of all the

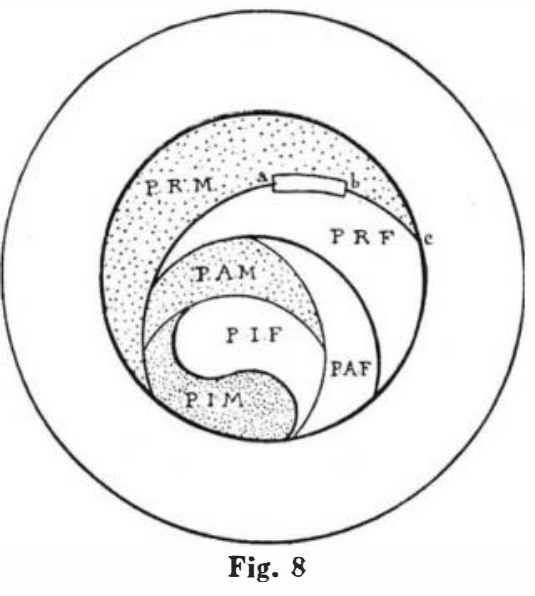

somatic cells to be born from this one, not by thousands but by millions. But we must not forget that we need explain and support only the non-fixed characters, or rather the action of these plasmas and characters upon the block of fixed plasmas and characters, and more precisely the morphologic modulations which the presence of these non-fixed characters impresses upon the ensemble of the fixed characters: it will suffice, then, to endow first the blastomers, then the embryonic cells derived from them, then all the cells of the body with the same structural characters in order for the ontogenesis to evolve smoothly, autcmatically, and with the great precision which is at times observed with respect to all possible heritable characters, without any exception.

Let us now consider the male chromatine making its perforaticn through the cytoplasma's corticality; let us appreciate its highly effective, infinitesimal but real mechanical "action," for if it is not measurable in human processes, none the less does it have enormous biologic consequences after it has succeeded in inciting the equivalent "reaction" on the part of the female chromatine; for if the rebound of this impulse does not entail the release of a whole cosmogony in the Cartesian manner, at any rate it is the point of departure of an embryogenesis, possibly of a human life, with all its possible consequences from the point of view of Race and Species.

It is easy to perceive, moreover, that the point of penetration of the spermatozoon into the ovule, and the molecular state in which it surprises the quiescent female plasmas, may also be of great importance for the future of the new creature.

As soon as this acccmmodation between the various plasmatic planes has been accomplished, there is a period of repose well known to cytologists, and of fixation in this state of mechanical and physico-chemical egiilibrium. And now we have defined a certain molecular structure peculiar to the new creature to come, and to it alone. We cuuld draw on paper the extremely enlarged geometric outline diagram by taking account of its projection on successive planes. And it is this microplasm of multiple, spheroidal segments of planes and of curves with infinitely varied intersections, which will remain fixed in this state, insofar as the laws of Chemistry permit.

Finally, in the gametes issued from a new individual, these plasmas may again become "defixed," (after the kineses of maturation, for example); but, eupposing that this arrangement be maintained throughout the individual somatic life until the mature genital elements be arrived at, the amphimixic shock to come will more $\mathbf{r}$ less upset this texture and these reciprocal relations of the P. N. F., relations which are thus made doubtful again, and must be resumed under a new type at each new amphimixia in the course of the specific life.

Observe that the present theory does not necessitate the addition of any substance whatever to the block of fixed plasmas and especially to the individual plasmas of each generation; but neither is there any impossibility that there may occur at certain moments of the specific life this extra or substitutive addition (mutation, saltation). And this marks the difference in the doctrine of the collocation of germs, which not being able to avo in each generation demands in a ver $y$ short time gametes of both sexes of the most improbable amounts.

The substance is given: it is sustained by the assimilative digestive synthesis; it is common, at time super- 
abundant, and common to such a point that there is no simple or composite body of low molecular weight which can be strictly specific; and the little that we know of the human plasmas authorizes us to believe that it is very similar to the plasmas of animals upon which it is nourished.

What is specific, is the intimate, molecular, molar, filamentary architecture of these plasmas; and that is not merely specific, but it is also racial, atavistic and individual; it is even older than the species, it belongs to the order, to the class, to the branch. The whole future individual has his outline "diagram" sketched, s.rstematized in this lowest protoplasmic sphere which the histologist can harden, dissect, and observe. But it is not a reduction of the corporeal form; it is useless to seek a reduction of the corporeal form; it is useless to seek
in it, as did Dalempatius and the first microscopists, a head and limbs: it is not a homunculus.

It is an abstraction, an idea.

It is hardly more material than a soul.

These are the geometric relations of a complication which is prodigious, but definite, fixed, almost immutable for this particular ovule, to the exclusion of every other in the entire universe, past or futcre. These are the possible planes of orientation, of directives for future cellular genesis, on condition that the specific plasma be furnished, continually and with entire purity first by the mother, then by the selective, alimentary autonomous synthesis during the remainder of growth.

$$
\text { VII-TRANSMISSION OF SEX }
$$

Of all the non-fixed characters, sex, with the secondary sexual characters, is the oldest, the most expressive, the one most generalized in the organism. It dominates all the others and impresses upon them something of one or another of its tonalities. Its position, therefore, must be somewhere on this concave spheroidal plane of the union and disunion of the fixed and the non-fixed plasmas; it envelops these and limits them towards the specific block, to which it has itself adhered from the remotest antiquity, for sex and the sexual characters are for the major part of specific order; but, since all the non-fixed characters, whether racial, atavistic, or paternal, are both paternal and maternal in origin, sex is also welded to their block and inseparable from it. We are familiar, for example, with the malformations of the epispadic or hypospadic meatus, and of the cryptorchidism. The secondary sexual characters (variation of the beard in man, of the crest and spur in the Gallinacea) may depend equally upon these three plasmatic origins. Consider Fig. 5 a little after the amphimixic shock for it is this which has just determined the sex of the offspring as can be readily perceived.

Under its influence the plasmatic caps are interlaced and arranged, those of paternal origin (dotted), rather towards the right hand and the bottom, those of maternal origin towards the left hand and the top. But we know that all these non-fixed plasmas whatever their nature and their origin, are also vehicles of sexual characters; and since it concerns characters reciprocally exclusive of each other, it is therefore the sex which, by the totalization of the surfaces of fixation of its plasmas repesentative of the specific block, will have the greatest extent of adhesions it is this which will have an ascendency over the other. Here it is the female sex, since $\mathrm{E} \mathrm{A}+\mathrm{A} \mathrm{B}+\mathrm{B} \mathrm{C}$ > $\mathrm{C} \mathrm{D}+\mathrm{DE}$; and the real proportion is very much greater than the plane figure indicates, since in reality it concerns the collocated spheroidal segments and complete spheroids.

The sex, therefore, is determined by that one of the two composite blocks which has literally "gotten the upper hand" with respect to the homologous and homodynamic plasmas of the other, which enters, therefore from this point of view, into the general case of latent characters.

Observe that if the least sliding of the plasmatic caps in one direction or the other has its consequence in the transfer of ordinary characters, this does not hold true for the sexual characters, and the arrangement of plasmatic planes which determines sex is something as primordial and irreversible as the paging of a printed, folded, and numbered book.

See how, in spite of the evident homodynamics of the plasmas of each sex, this mode of covering, of effacing, this eclipse of the plasmas of one sex by those of the other accounts for the ulterior automatic development of the qualities proper to the sex of the enveloping plasma. Moreover, one need only enlarge as much as one wishes one of the caps with respect to the other to represent the material basis of the morphologic differences, so curious and sometimes so striking, which exist between the two sexes throughout the whole extent of the animal kingdom.

The egg type of Fig. 5 also enables us to comprehend another celebrated antinomy very simply solved by the present theory, that of the off spring resembling solely, or almost solely; one of its parents, while having the sex of the other. In this case it is a female $(\mathrm{E} \mathrm{A}=\mathrm{A} \mathrm{B}=\mathrm{BC}$ $>\mathrm{C} \mathrm{D}=\mathrm{D}$ E) which has as maternal characters only those represented by a trifling adhesion in B C; it will strongly resemble its father, on the contrary, by reason of the large surface

The rarity or

The rarity or impossibility of true hermaphroditism probability af a prectreme im probability of a precisely equilibrated partition of th plasmas of each sex; thus the type represented by Fig. 6 , wherein the segment of fixation A B C D is perceptibly equal to the segment A F E D, has infinitely few chances of being realized subsequent to the amphimixic shock and one even perceives in $\mathrm{A}$ an inevitable plasmatic projection of the segment $?$ upon the segment ${ }_{\downarrow}$, which distributed would suffice to turn the scale and decide the appearance of the male sex.

\section{VIII-OSCILlating SPECIES}

Dur diagram of the fecundated egg adapts itself with great flexibility to the exceptional cases which biology may be called on to explain. Below is one of these taken as an example among many others which the plane of this article does not permit us to enumerate systemmatically.

It is the case (Fig. 7), wherein the individual character of the genitors are never transmitted, the corresponding plasmas, because of density or for some other reason, not being able to come in contact with the specific block at any point. Such species oscillate indefinitely around a single type or a very small series of types. The in dividuals strangely resemble each other.

These species stand apart from all mutation and al progress until the moment when these innovation plasmas, which until now have remained inactive and impotent come, under one influence or another (increase of their volume or their density), to take their place, their surface of contact with the zone of manifestation, the historic zone of the species, and to play their contributory part to the morphology of individuals.

IX-APPLication TO A CONCRETE CASE; HEREDITy IN THE COLORATION OF THE FUR IN MICE

The biometricians have taught us that there exist in mice unit characters, each of which corresponds, in the Weissmanian "germinative plasma," to a determinant capable of independent variation; but the concrete descriptive character may be in relation with one or mor determinants which can be made evident only by well directed crossing

The present theory should be able to demonstrate how the internal relations of these characters can be simplified: by the reciprocal play of plasmatic material masses we shall be enabled to substitute for some of them others which are more comprehensive, and to bring out the true nature of certain abstract characters, the creation of human nomenclatures of which no plasma could be the vehicle.

By limiting ourselves to that which has reference to the determinants of color, which are at once rather complicated yet quite measurable, we shall be able to form an idea of the advantage to be derived from the theory with respect to simple cases.

From this point of view Cuénot has recognized in mice the independent existence of the following determinants: 1.-A determinant of the general color $\mathrm{C}$, which exists in all pigmented mice (and perhaps in all the pigmented Vertebrata).

2.-Its mutation A corresponds to the absolute deprivation of color (Albinism), whatever be the other determinants of the hereditary formula.

3.-A determinant $\mathrm{M}$, which accompanied by $\mathrm{C}$ is in proportion with the black color of the eyes; its mutation $\mathrm{E}$ corresponds to the red color of the eyes and lightens the general tint.

4.-In the presence of $\mathrm{C}$ there are three special determinants of color; yellow J, gray G, and black N, the first dominating the second, which dominates the last.

5.- $\mathrm{U}$ is a determinant of the uniform coloration of the fur, whatever be its tint; it is capable of a mutation $\mathrm{P}$, which represents a more or less extensive streaking.

Let us now represent the possible arrangement of are racial, or ancestral, preferably racial. Dissociating in imagination one of the spheroidal segments of the in imagination one of the spheroidal segments of the
plasmatic masses constituting the amphimixic chromatplasmatic masses constituting the amphimixic chromat-
ine, we obtain a filament comparable to one of those chromatic filaments which the miscroscope has enabled us to recognize, and we must admit that what we have before us is precisely the vector filament of chromatic characters for the fur of mice. ${ }^{7}$

'It is very easy to localize this fllament upon any spheroid whatever of the block of non-fixed characters: Upon figure 8, fo
example, this filament will be an element $A B$ situated on the zon
There are two cylindroidal plasmatic masses very similar in quality and in dimensions in the filamental segment furnished by each sex after the amphimixis. We may therefore give the name of amphimixic chromophoric plasma to each of these masses P C A M, P C A F, (Fig. 9) which may, and even must, remain in effective continuity with other formative plasmas $\mathrm{X} \mathrm{M}, \mathrm{X} \mathrm{F}$, not endowed with chromophore qualities, whose presence bears no relation to the transmission of pigmentation. These mobile filamental segments slide over each other during the period of gropings and arrangement following the shock of the male and female chromatines, yet seek, nevertheless, to attach and fix themselves to one another, in virtue of the reciprocal attraction of the homologous plasmas, which has been accepted as a highly probable postulate dominating all the amphimixic mechanism.

We have supposed, moreover, that the couple of the two filaments is in a suitable situation with respect to an adjacent zone of the specific plasma of this zone of manifestation which permits the characters to escape from the latent condition. But since we are concerned, in the example chosen, with racial characters exclusive of each other by couples, it is necessary besides, in order for the character studied to have all its value, all its plenitude, that it should establish a certain extent of adhesions between the two homologous plasmatic segments of each

It suffices, therefore, to make one of the two plasmatic ribbons slide over the other in order to observe the various positions capable of translation into the characters of the product.

Fig. 9 presents the maximum adhesion, i.e., the total of the amphimixic chromophore plasmas P C A M and P C A F; no adhesion with the adjacent non-chromophore plasmas X M, X F; i.e., which one must by exclusion, consider as determinants of the white color or color of depigmented tissues. It concerns, therefore, the maximum pigmentation for the mouse studied. If we take it that the chromophore segment in question is the vehicle of black $\mathrm{N}$, this simple figure gives us at a single stroke, the explanation of the three determinants: 1.-Determinant $\mathrm{C}$, color in general, human concept, an abstraction without corresponding vector plasma.

2.-Determinant $\mathrm{N}$, black color, with a corresponding plasmatic segment in the chromosomes.

3-Determinant $U$, uniformity of fur, human concept, abstraction without special vector plasma, yet represented, nevertheless, by something material, the total adhesion and fixation of the homologous plasmas $\mathbf{N}$, which must tend to reproduce themselves, perhaps in all the blastomeres, perhaps in all the cells of the body, but surely in all the ectodermic line, whence issue the epidermic epitheliums and the colored hairs. Another type: Before the fixation has become definite the plasmastic ribbons have slipped over each other in opposite directions (Fig. 10) as the arrows indicate. They have stopped at the position determined by X M-F Y: $i$. e., the average adhesion in $\mathrm{M} \mathrm{F}$ between the chromophore plasmas; considerable adhesions in $\mathrm{X} \mathrm{M}$ and $\mathrm{F} \mathrm{Y}$ with adjacent non-chromophore plasmas. New result: Streaking, $i$. e., mutation $\mathrm{P}$ of determinant $\mathrm{U}$.

Streaking, $i . e$. , mutation $\mathrm{P}$ of determinant $\mathrm{U}$.
Intervention of three determinants: $\mathrm{C}, \mathrm{N}, \mathrm{P}$ (the latter exclusive of $U$ ).

Another type: In spite of the attraction of the homologous plasmas, the sliding in the direction of the arrows is accentuated. There is no longer any contact or fixation between the chromophore plasmas, which lose their hereditary dynamic values, which apparently cease to exist, and which become the bearers of latent characters (Fig. 11).

Definite adhesions establish themselves in X F, M Y, with any non-chromophore plasmas whatever.

Result: Absence of pigmentation. Albinism Intervention of four determinants, C, N, U, A. C, U, A, are always abstractions, without possible corresponding plasma; and observe that $\mathrm{N}$, which is alone in possessing a material substratium, loses all hereditary value by this simple exaggerated gliding of a few fractions of a micron. And the theory, far from claiming for albinism a corresponding and supernumerary particle, not only economizes it, but unexpectedly lightens it in its en albinism to the domain of abstractions.

$\mathrm{x}$ - Plasmas AND Determinants JOINEd By COUPLES OR BY GROUPS

Every one knows that among living creatures certain

of contact of the male racial plasmas (dotted segment) with the corresponding female racial plasmas. A plane figure does not permit us to represent at the same time their common adhesion to the surrounding specific plasma, which does not seem to occur
except at the point $c$; in reality, since it concerns spheroidal caps, except at the point $c$; in reality, since it concerns spheroidal caps,
this necessary triple intersection is pursued along a curved line this necessary triple intersection is pursued along a curved line
projected somewhere in front of the plane of the figure and which projected somewhere in front of the plane of
can easily be reestablished in imagination. This observation is valid for all the diagrams of the nuclear
spheroid utilized in the course of this article. 
characters are very closely united, manifesting themselves or failing to do so, together; all the specific character behave in this way; a horned mammal does not have retractile nails, and a mammal with retractile nails is never horned.

The present theory, naturally, will furnish a convenien representation with regard to the non-fixed characters, which derives from the preceding paragraph and completes it.

Take the two plasmatic ribbons of cylindrical segment and triangular section $\mathrm{M}$ A B, F C D (Fig. 12), constituting a distinct part of the total chromophore batonnets $\mathrm{X} \mathrm{X}^{1}, \mathrm{~A} \mathrm{~B}, \mathrm{Y} \mathrm{Y}^{1} \mathrm{C}$. These two elements are joined together materially, as the characters they reprecent are united solidly in ontogenesis. Let us attribute as a determinant to this triangular sector the production of the black pigment of the eyes. The extent of its adhesions with the corresponding homodynamic sector will give the following results, the sliding occurring in the direction of the arrows:

1.- If the movement stops at the stage of Fig. 12 simultaneously and conjointly, and important adhesion in M F, will produce black eyes, at the same time that the long adhesion, which is more general, more comprehensive, and projects beyond the first, i. e., X M F Y, composed of plasmas of the total chromogene type $N$, will give the dark color to the fur.

The intervention of four determinants C, P (slight streakings because of achromic adhesions in $\mathrm{C} \mathrm{X}^{1}$ and $\mathrm{Y} \mathrm{B),} \mathrm{N,} \mathrm{M} \mathrm{which} \mathrm{is} \mathrm{a} \mathrm{special} \mathrm{plasma.}$

2.-The sliding is continued. The useful adhesion of the chromogene determinant of the eyes is reduced to the line M F (Fig. 13).

The eyes will be black, for these organs are selectively charged with pigment, even when its proportion in the organism is limited. The fur will be streaked, with predominance of light borders, $\mathrm{C} \mathrm{X}^{\mathbf{1}}+\mathrm{Y} \mathrm{B}$, achromic zones, being superior to $\mathrm{X} Y$, the middle plane of fixation of the plasmas which are the vehicle of color, and this lightening of color will be proportional to the surfaces of adhesion with the adjacent achromic plasmas. It is the beginning of the mutation $E$. The intervention of five determinants $\mathrm{C}, \mathrm{P}, \mathrm{N}, \mathrm{M}, \mathrm{E}$, of which two alone are concrete and material $(\mathrm{N}, \mathrm{M})$.

3.-The sliding is exaggerated until it definitely disunites the homologous chromogene zones (Fig. 14).

This gives total albinism, since the plasmas of the general color are brought to the position of Fig. 11, and the plasmas which are the vehicles of color are now united only to the achromic segments in C F and M B. There is no choroidal pigmentary manifestation, whence the red eyes of the albino. Here there is an intervention, or rather an unfolding of six determinants, namely: four determinants $\mathrm{C}, \mathrm{A}, \mathrm{E}, \mathrm{U}$, which are abstractions in any case, and finally, "for annulment", in the state of latent characters, of the two determinates $M, N$, which are plasmatic.

$$
\text { [TO BE CONTINUED] }
$$

\section{Titanium in the Metallurgy of Iron}

General Statement.-The effect of titanium on cast iron has been the subject of much discussion; not a great amount of data is available for the accurate solution of the question, but the probabilities are that the action of the metal has quite contradictory effects. This is presumed to raise from its varying action with the different metalloids. In an extensive paper in 1912 before the American Institute of Mining Engineers, Bradley Stoughton recorded data pertinent to the effect of titanium on the strength of cast iron. One particular point is to be ncted from his findings, for the reason that it stands forth very prominently, and that is that titanium unquestionably reduces the chill. Thi should nct be unexpected from what is known of the action of the metal-it being one of the strongest deoxidizers known, and it further has a high chemical affinity for both sulphur and nitrogen. The question logically arises: Why does titanium reduce chill? This is readily answered. The elements oxygen and sulphur (and nitrogen, probably) are productive of chill, and titanium, by removing them, consequently removes their chill action. This shows how the chill is modified and, further, why the strength of castings is lower. The titanium not only removes the sulphur but also the oxygen $^{1}$. The effect of titanium in reducing chill in cast iron is overcome by the use of an increased proportion of manganese for purposes of restoration-and thi is decidedly met with disapproval. It appears, on the whole, that not much benefit can arise from using titan-

1 The effect of small amount of oxygen in cast iron is to in crease its strength and resistance to shock. Oxygen to the 3500 pounds per square inch, as compared with 2500 pounds pe square inch for otherwise similar non-oxygenated iron. Note Johnson, W. McA., "A Chemical Explanation of the Effect of
Oxygen in Strengthening Cast Iron," Bull. A. I. M. E., FebruOxygen in Strengthenin
ary, 1916, pp. 233-235. ium in the metallurgy of cast iron, but recently its use has been recommended by Doctor Moldenke the American foundry expert, as worthy of employment for the removal of nitrogen and oxygen where special cast irons are to be produced. Some metallurgists held for a long time that titanium rendered cast iron tough-probably, for one reason, because the well-known pig iron of Upper Styria contains a small percentage of the metal. However, steel made therefrom rarely showed any titanium
content on analysis, because of the strong affinity of the element for oxygen.

How Titanium is Used in Iron Metallurgy.-In iron foundry practice, the usual method of employing titanium is to scatter a predetermined c.mount of a titaniun alloy (ferro-titanium or ferro-carbon titanium, as th case may be) along the runner prior to tapping. Upon tapping the cupola, the titanium alloy is washed into the ladle with the stream of iron. As in steel practice, tim should be allowed for the chemical reactions to complete themselves, so that the ladle should be held for about three minutes before pouring. Also, as in steel practice, care should be taken so that the slag be not allowed to come in contact with the alloy, as slag at tacks the alloy with very great avidity, thus destroyin its function. Iron may also be treated in the ladle by adding the titanium alloy to the ladle either before or during tapping. In small hand ladles it is an easy matter to stir the iron with a rod in order to thoroughly incorporate the alloy into the molten bath. For usual deoxidizing purposes, about two to four pounds of a 15 per cent titanium alloy per ton of iron will be requisite and sufficient.-From a paper on the Metallurgy of the Journalof the Franklin Institute.

\section{Sugar Industry in India}

THE question of encouraging the extension of sugar production in British territories is one that is now being considered by the Government. In fact sugar has become such an important commodity and so much prominence has been given to the striking fact of the British Empire's dependence upon foreign countries for supplies which might be produced within the empire, for instance beet sugar in the United Kingdom and cane sugar in other countries of the empire, that it is of importance to consider this question. Due attention is being given in India to the problem of increasing the output of sugar. India's production of cane sugar is about two and a half million tons a year, but this quantity is not sufficient for home consumption, and consequently some 600,000 tons are imported, mainly from Java and before the war from Mauritius. The average yield of sugar for the whole of India is about one and one-quarter tons per acre; in Java three tons per acre are obtained and about the same amount in Cuba, while in Hawaii five tons of sugar per acre are sometimes produced. To double the production of sugar in India per acre by improved methods of cane extraction would appear at first sight to be a simple matter and such a result would not only be of great profit to the native planter but would also provide a surplus for export to the world's markets. As a matter of fact the development of the sugar industry in India is a very large problem and full of difficulties, but it need not be supposed that the problem is insoluble or the difficulties insuperable. The Government of India is giving the subject constant attention, but it would appear that several years may elapse before substantial results are obtained. Among the numerous questions to be studied are the varieties of sugar cane suitable for particular localities, the relative values of the indigenous "kinds compared with those introduced and the soil treatment which will be the best for ensurin steady growth and a good yield of juice. The Government of the United Provinces is making a practical attempt to manufacture sugar on a European factory system, and this is an endeavor to advance a step beyond the careless and wasteful native methods of sugar extraction and at the same time avoiding the ideal of the large central factory system which cannot be attained at present. At Nawabganj in the Bareilly district a sugar factory has been established by state efforts, and a first report has been made by Messrs. Hulme and Sangchi on the results obtained. It seems that at first the idea of improving the native sugar-making methods appeared an easy one to realize, but the experience of a year or two has now convinced the authors that the mere introduction of crushing mills requiring greater animal power would prove no advantage to the planters, who in most cases have not capital enough for an outlay in an expensive plant. The greatest obstacles appear to be the jealousy of the sugar boilers who see in the improvements offered a menace to their old and absolete methods, as well as the obstinate resistance to innovations of any kind on the part of the native planter. These are serious difficulties, it must be admitted, but These are serious difficulties, it must be admitted, but
they are obstacles of the kind that have often had to be overcome in carrying out progressive methods and any rate it is gratifying to note the interest that the Government is taking to increase the output of sugar in India, for this will not only improve the position of the native planter but also confer a benefit on the whole empire.-London Chamber of Commerce Journal.

\section{Timber Use for Trench Building}

Reliable estimates of the amount of timber which has gone into the shoring up of trenches and dugnots, into the miles and miles of trench sidewalks and corduroy roads, and into artillery and trench screens are not available, but the quantity, on the hundreds of miles of front, surely totals up to several hundreds of millions of feet. On the statement of a French colonel it is learned that as high as 30,000 trees were used daily by a single French army corps.

\section{SCIENTIFIC AMERICAN SUPPLEMENT

\author{
Fouuded 1876
}

NEW YORK, SATURDAY, JANUARY 26, 1918

Published weekly by Munn \& Company, Incorporated '
Charles Allen Munn, President: Frederick Converse Beach,
Secretary: Orson D. Munn, Treasurer Secretary: Orson D. Munn, Treasure
all at 233 Broadway, New York

Entered at Post Offce of New York, N. Y., as Second Class Matter
Copyright 1917 by Munn \& Co. Inc. The Scientific American Publications Scientific American Supplemone (established 1876) per year $\$ 5.00$
Scientifl American (estabtished 1845) The combined subscription rates and rates to foreign countries,
Including Canada, will be furnished tpon applctatfon.
Remit by postal or express money order, bank araft or check.

Munn \& Co., Inc., 233 Broadway, New York

The purpose of the Supplement is to publish the more important announcements of distincles that appear in European publications, and cles that appear in European publications, and altogether to reflect the most advanced thous
in science and industry throughout the world.

Back Numbers of the Scientific American Supplement

Supplements bearing a date earlier than January 1st, 1917, can be supplied by the $\mathrm{H}$. W. Wilson Company, 958-964 University Ave., Bronx, New York, N. Y. Please order such back numbers from the Wilson Company. Supplements for January 1st, 1917, and subsequent issues can be supplied at 10 cents each by Munn \& Co., Inc., 233 Broadway, New York

$W_{E}$ wish to call attention to the fact that we are in a position to render competent services in every branch of patent or trade-mark work. Our staff is composed of mechanical, electrical and chemical experts, thoroughly trained to prepare and prosecute all patent applications, irrespective of the complex nature of the subject matter involved, or of the specialized, technical, or scientific knowledge required therefor.

We also have associates throughout the world, who assist in the prosecution of patent and trade-mark applications filed in all countries foreign to the United States.

\section{Branch Office:}

625 F Street, N. W.

Washington, D. C.

M ONN \& Co.,

Patent Solicitors,

233 Broadway,

Table of Contents

The Submarine-By Marley F. Hay

Manufacture of Smokeless Powder................... 2 illustrations. ...

e Banana as a Food...

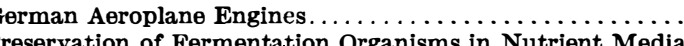

Preservation of Fermentation Organisms in N. Clankson

Science of Bricklaying.

A Large Electromagnet..........................
Women in Technical Work -5 illustrations.

Machining vs Metal ....

Biochemistry of Plants...

Light-By w. w. Campell...

Protection Against Noise and Vibration.....

The Biological Aspects of Warfare-III-By Harry Campbell

A Problem of Wooden Shipbuilding - By Bror L. Grondal ...

The Collocation of the Plasmas Within the Cell-I-By Louis

Titanium in the Metallurgy of Iron

Sugar Industry in India. 